\title{
Prevalence and Management of Coronary Chronic Total Occlusions in a Tertiary Veterans Affairs Hospital
}

\author{
Omar M. Jeroudi, MD ${ }^{\star}, \dagger$, Mohammed E. Alomar, MD ${ }^{*}, \dagger$, Tesfaldet T. Michael, MD, MPH ${ }^{\star}, \dagger$, \\ Abdallah El Sabbagh, MD ${ }^{*}, \dagger$, Vishal G. Patel, MD ${ }^{*}$, , Owen Mogabgab, MD ${ }^{*}, \dagger$, Eric Fuh, \\ MD $^{*}, \dagger$, Daniel Sherbet, MD ${ }^{*}$, , Nathan Lo, MD ${ }^{*}, \dagger$, Michele Roesle, RN, BSN ${ }^{\star}$, Bavana V. \\ Rangan, BDS, MPH${ }^{*}$, Shuaib M. Abdullah, MD* ${ }^{*}$, , Jeffrey L. Hastings, $\mathbf{M D}^{*}, \dagger$, Jerrold Grodin, \\ MD $^{*}, \dagger$, Subhash Banerjee, MD $^{*}, \dagger$, and Emmanouil S. Brilakis, MD, PhD ${ }^{*}, \dagger$ \\ *Veterans Affairs North Texas Healthcare System, Dallas, Texas \\ †University of Texas Southwestern Medical Center, Dallas, Texas
}

\begin{abstract}
Objectives-We sought to determine the contemporary prevalence and management of coronary chronic total occlusions (CTO) in a veteran population.

Background-The prevalence and management of CTOs in various populations has received limited study.

Methods-We collected clinical and angiographic data in consecutive patients that underwent coronary angiography at our institution between January 2011 and December 2012. Coronary artery disease (CAD) was defined as $250 \%$ diameter stenosis in $\geq 1$ coronary artery. CTO was defined as total coronary artery occlusion of $\geq 3$ month duration.
\end{abstract}

Results-Among 1,699 patients who underwent angiography during the study period, 20\% did not have $\mathrm{CAD}, 20 \%$ had CAD and prior coronary artery bypass graft surgery (CABG) and $60 \%$ had CAD but no prior CABG. The prevalence of CTO among CAD patients with and without

Corresponding author: Emmanouil S. Brilakis, MD, PhD, Dallas VA Medical Center (111A), 4500 South Lancaster Road, Dallas, TX 75216, Tel: (214) 857-1547, Fax: (214) 302-1341, esbrilakis@yahoo.com.

Disclosures:

Dr. Jeroudi: none

Dr. Alomar: none

Dr. Michael: Cardiovascular Training Grant from the National Institutes of Health Award Number T32HL007360.

Dr. El Sabbagh: none

Dr. Patel: none

Dr. Mogabgab: none

Dr. Fuh: none

Dr. Sherbet: none

Dr. Lo: none

Ms. Roesle: none

Dr. Rangan: none

Dr. Abdullah: none

Dr. Hastings: none

Dr. Grodin: none

Dr. Banerjee: Speakers' Bureau for St. Jude Medical Center, Medtronic Corp., and Johnson \& Johnson; research grant from Boston Scientific.

Dr. Brilakis: consulting fees/speaker honoraria from St Jude Medical, Terumo, Janssen, Sanofi, Asahi, Abbott Vascular, and Boston Scientific; research support from Guerbet; spouse is an employee of Medtronic 
prior CABG was $89 \%$ and $31 \%$, respectively. Compared to patients without CTO, CTO patients had more comorbidities, more extensive $\mathrm{CAD}$ and were more frequently referred for CABG. Percutaneous coronary intervention (PCI) to any vessel was performed with similar frequency in those with and without CTO (50\% vs. 53\%). CTO PCI was performed in $30 \%$ of patients without and $15 \%$ of patients with prior CABG with high technical (82\% and $75 \%$, respectively) and procedural success rates (80\% and $73 \%$, respectively).

Conclusions-In a contemporary veteran population, coronary CTOs are highly prevalent and are associated with more extensive comorbidities and higher likelihood for CABG referral. PCI was equally likely to be performed in patients with and without CTO.

\section{Keywords}

coronary occlusion; percutaneous coronary intervention; coronary artery disease

\section{Introduction}

The contemporary prevalence and management of coronary chronic total occlusions (CTO) has received limited study and vary significantly in different patient populations (1-4). Patients with CTOs are more likely to be referred for coronary artery bypass graft surgery $(\mathrm{CABG})$ and less likely to undergo percutaneous coronary intervention (PCI) $(1,5,6)$, however, the choice of coronary revascularization strategy is highly dependent on local practice patterns and expertise. Recent developments in CTO PCI techniques have enabled high procedural success rates, while maintaining low risk for procedural complications (711). These developments are especially important for the veteran population, which is known to have high coronary artery disease (CAD) burden (12). The goal of the present study was to evaluate the prevalence and contemporary management of coronary CTOs at a Veterans Affairs tertiary referral center with expertise in CTO PCI.

\section{Materials and Methods}

\section{Patients}

We retrospectively reviewed the coronary angiograms and medical records of all consecutive patients who underwent diagnostic coronary angiography at our institution between January 1, 2011 and December 31, 2012. Clinical information such as demographics, cardiac history, comorbidities, procedural data and outcomes, and cardiac catheterization results were collected and analyzed to evaluate for the prevalence and clinical management of patients with coronary CTOs. Of the patients who had multiple cardiac catheterizations during the study period, only the first procedure was included in the present analysis. Patients who underwent angiography as part of a research protocol were excluded if the index cardiac catheterization occurred prior to January 1, 2011. The study was approved by the institutional review board of our institution.

Significant CAD was defined as $\geq 1$ lesion of $\geq 50 \%$ luminal diameter stenosis. CTO was defined as a total coronary artery occlusion of $\geq 3$ month duration with Thrombolysis in Myocardial Infarction (TIMI) 0 flow. Estimation of occlusion duration was based on first onset of anginal symptoms, prior history of myocardial infarction in the target vessel 
territory, or comparison with a prior angiogram. The decision to undergo CTO revascularization was at the discretion of the interventional cardiologist and the patient. CTO PCI technical success was defined as successful CTO revascularization with achievement of $<30 \%$ residual diameter stenosis within the treated segment and restoration of TIMI grade 3 antegrade flow. CTO PCI procedural success was defined as technical success without in-hospital major adverse cardiac events (MACE). In-hospital MACE included any of the following adverse events prior to hospital discharge: death from any cause, Q-wave myocardial infarction, recurrent angina requiring urgent repeat target vessel revascularization with PCI or coronary bypass surgery, tamponade requiring pericardiocentesis or surgery, or stroke.

\section{Statistical Analysis}

Continuous parameters were presented as mean \pm standard deviation and compared using the student's $t$ test or Wilcoxon rank-sum test, as appropriate. Nominal parameters were presented as percentages and compared using Pearson's chi-square test. A p value $<0.05$ was considered statistically significant. Statistical analyses were performed using JMP 10.0.2 software (SAS Institute, Cary, North Carolina).

\section{Results \\ Patients}

Between January 1, 2011 and December 31, 2012, 1,699 consecutive patients underwent diagnostic coronary angiography at our institution; $80 \%$ of them had CAD (20\% with and $60 \%$ without prior CABG, Figure 1). At least one coronary CTO (total of 1,003 CTO lesions) was present in 624 patients. The prevalence of CTO was $37 \%$ among all patients and $46 \%$ among patients with CAD. The prevalence of coronary CTOs among CAD patients without prior $\mathrm{CABG}$ was $31 \%$ while the prevalence of coronary CTOs among CAD patients with prior CABG was $89 \%$ (Figure 1).

\section{CTO in patients with CAD and without prior CABG}

At least one CTO was present in 319 of 1,015 patients (31\%), who had a total of 402 CTOs ( $24 \%$ of patients had $>1$ CTO). Compared to patients without a CTO, patients with a CTO were more likely to have both cardiac and non-cardiac comorbidities, presented more frequently with stable angina and had more extensive CAD (Table I). In the 244 patients with 1 CTO, most CTOs were located in the right coronary artery (RCA) (59\%), followed by the circumflex (21\%) and left anterior descending artery (LAD) (20\%). Most RCA and LAD CTOs were located in the proximal or mid-vessel segment, whereas circumflex CTOs were more evenly distributed along the vessel (Figure 2). Thirty-two of the 402 CTOs (8\%) were due to in-stent restenosis (ISR) in 31 patients.

Coronary revascularization was performed in $81 \%$ of the CTO patients versus $69 \%$ of the non-CTO patients ( $<<0.001$, Table I and Figure 3$)$. CTO patients were more likely to undergo $\mathrm{CABG}$, but equally likely to undergo $\mathrm{PCI}$ to any vessel compared to patients without a CTO. CTO PCI was attempted in $30 \%$ of the CTO patients with $84 \%$ per patient procedural success rate (79 of 94 patients, Figure 3). Patients with prior myocardial 
infarction, peripheral arterial disease, and chronic kidney disease were more likely to receive medical therapy without coronary revascularization (Table II). Patients with left main disease, 3-vessel disease, or a circumflex CTO were more likely to undergo CABG than PCI, whereas patients with 1 or 2-vessel disease CAD and LAD CTOs were more likely to undergo PCI.

Forty-six patients presented with acute ST-segment elevation myocardial infarction, eight of whom $(17 \%)$ had a non-culprit CTO. All eight patients underwent primary PCI of the culprit vessel and one patient subsequently underwent CABG. CTO PCI was later attempted in two patients $(29 \%)$ with a technical success rate of $50 \%$.

\section{CTO in patients with CAD and prior CABG}

During the study period, 305 of 344 patients (89\%) with prior CABG were found to have 601 CTO lesions ( $66 \%$ of whom had >1 CTO). A total of 21 CTO lesions (3.5\%) in 19 patients were due to in-stent restenosis. PCI was performed in 182 patients $(60 \%)$ of whom 46 patients (15\% of total) underwent CTO PCI (Figure 4$)$. Two patients $(0.6 \%)$ underwent redo $\mathrm{CABG}$, whereas the remaining $40 \%$ received medical therapy only.

\section{CTO PCl outcomes}

During the study period, 152 CTO PCI attempts were made in 140 patients with an $80 \%$ technical success rate (78\% procedural success). Technical success was $82 \%$ among nonprior $\mathrm{CABG}$ patients and $75 \%$ in prior $\mathrm{CABG}$ patients $(80 \%$ and $73 \%$ procedural success rates, respectively). The CTO PCI attempt rate was significantly higher among patients without prior CABG (58\% vs. $25 \%$, p $<0.001)$. Major complications in CTO PCI patients occurred in four patients $(2.9 \%)$ : two patients had post-procedural myocardial infarction (one of whom died), one patient had concomitant PCI of a non-CTO lesion which required urgent revascularization due to stent thrombosis, and one patient had an acute stroke.

\section{Discussion}

The main findings of this study are that: (a) the prevalence of CTO in non-CABG patients with CAD was $31 \%$; (b) LAD and RCA CTOs were located mostly in the proximal and midvessel segments, whereas circumflex CTOs were more evenly distributed throughout the vessel; (c) patients with CTO were more likely to be referred for CABG but were equally likely to receive PCI to any vessel as those without CTO; and (d) CTO recanalization was attempted in nearly one third of patients with CTO lesions with high success and low complication rates.

The reported prevalence of CTOs among patients undergoing cardiac catheterization varies widely. In the largest study reported to date (prospective 3-center Canadian registry), the prevalence of CTO was $18.4 \%$ among patients with CAD (defined as $250 \%$ stenosis in $\geq 1$ vessel) without prior CABG and 54\% among patients with prior CABG (1). Using the same definition of CAD, Kahn et al. identified a CTO in $35 \%$ of 287 patients with CAD at a single institution within one year (2). In a German multicenter prospective registry spanning 64 hospitals and private practices, Werner et al. reported a CTO prevalence of 33\% in 2,002 patients presenting with stable angina and first angiographic diagnosis of CAD (4). In a 
previous study investigating the frequency of CTO in a veteran population, Christofferson et al. reported a CTO prevalence of $52 \%$ in patients with CAD (defined as $\geq 70 \%$ stenosis in $\geq 1$ vessel) and an overall prevalence of $24.5 \%$ in 8,004 non-CABG patients undergoing diagnostic angiography over a ten year period (3). The contemporary prevalence of CTOs in our veteran population was $31 \%$ among non-CABG patients presenting with CAD, which is higher than the prevalence reported by Fefer et al., but similar to the prevalence reported by Kahn et al. and by Werner et al. Moreover, nearly all (89\%) patients with prior CABG had a CTO, which is higher than the prevalence reported by Fefer et al. for prior CABG patients (54\%). One potential explanation may be greater CTO burden in this group prior to CABG; however, an alternative explanation may be the rapid progression of proximal disease with subsequent occlusion of the bypassed vessels $(13,14)$.

Approximately half of the CTO lesions in our study were located in the RCA territory with the majority in the proximal and mid-vessel segments of the coronary vasculature. This is similar to what has been reported in other populations, in which RCA CTOs account for $47 \%$ to $64 \%$ of all CTO lesions; moreover, more than half of these occlusions are located within the proximal or mid coronary artery segment (1-4).

Similar to prior studies $(1,15)$, patients with CTOs in our cohort were more likely to undergo CABG compared to non-CTO patients ( $30 \%$ vs. $16 \%, p<0.001$ ), which is consistent with the superior clinical outcomes of CABG compared to PCI among patients with advanced multivessel coronary artery disease (16). In contrast to prior studies, the rate of PCI to any vessel in patients with a CTO was comparable to that of patients without a CTO (50\% vs. $53 \%, \mathrm{p}=0.48)$. The CTO PCI attempt rate in our population $(15 \%$ and $30 \%$ for patients with and without prior $\mathrm{CABG}$, respectively) is significantly higher than the attempt rate reported in prior studies $(10 \%-13.6 \%)(1,5)$. This is likely related to (a) the high prevalence of CTO in our population; (b) high cardiac and non-cardiac disease burden of the study patients; and (c) local expertise in treating CTOs. Our study did not perform longitudinal follow-up to detect long-term outcomes post PCI, however, successful CTO PCI has been associated with significant improvements in angina and left ventricular ejection fraction as well as a reduced need for subsequent CABG $(17,18)$. A decision to proceed with CTO PCI should always take into account the risk for complications (7). CTO PCI success rates were lower among prior CABG patients, consistent with a recent report from a multicenter CTO PCI registry (19).

\section{Limitations}

Our study has important limitations. Nearly all patients were men (as expected in a veteran population) and the study findings may not be extrapolated to women. Clinical outcomes and improvement in symptoms related to management chosen are not reported, therefore no conclusion can be made on the effect of increased percutaneous revascularization rates of CTOs in this population. Moreover, coronary revascularization (with either PCI or CABG, including CTO PCI) carries risks for complications that should be carefully weighed against the potential benefits. The external validity of our study findings may be limited by the wide variability in the CTO attempt and success rates among various institutions and various populations. 


\section{Conclusions}

In conclusion, our study demonstrates that in a contemporary cohort of veterans referred for cardiac catheterization, nearly one in three non-CABG patients with significant $\mathrm{CAD}$ were found to have a CTO. Compared to patients without a CTO, СТО patients had more comorbidities, were more likely to undergo CABG, but were equally likely to undergo PCI to any vessel. CTO PCI was associated with high success and low complication rates.

\section{Abbreviations}

$\begin{array}{ll}\text { BMI } & \text { body mass index } \\ \text { CABG } & \text { coronary artery bypass graft } \\ \text { CAD } & \text { coronary artery disease } \\ \text { CHF } & \text { congestive heart failure } \\ \text { CKD } & \text { chronic kidney disease } \\ \text { CTO } & \text { chronic total occlusion } \\ \text { CVA } & \text { cerebrovascular accident } \\ \text { ISR } & \text { in-stent restenosis } \\ \text { LAD } & \text { left anterior descending artery } \\ \text { LCx } & \text { left circumflex artery } \\ \text { LVEF } & \text { left ventricular ejection fraction } \\ \text { MACE } & \text { major adverse cardiac event } \\ \text { MI } & \text { myocardial infarction } \\ \text { OM } & \text { obtuse marginal artery } \\ \text { PCI } & \text { percutaneous coronary intervention } \\ \text { RCA } & \text { right coronary artery } \\ \text { TIMI } & \text { Thrombolysis in Myocardial Infarction }\end{array}$

\section{References}

1. Fefer P, Knudtson ML, Cheema AN, Galbraith PD, Osherov AB, Yalonetsky S, Gannot S, Samuel M, Weisbrod M, Bierstone D, Sparkes JD, Wright GA, Strauss BH. Current perspectives on coronary chronic total occlusions: the Canadian Multicenter Chronic Total Occlusions Registry. J Am Coll Cardiol. 2012; 59(11):991-7. [PubMed: 22402070]

2. Kahn JK. Angiographic suitability for catheter revascularization of total coronary occlusions in patients from a community hospital setting. Am Heart J. 1993; 126(3 Pt 1):561-4. [PubMed: 8362709]

3. Christofferson RD, Lehmann KG, Martin GV, Every N, Caldwell JH, Kapadia SR. Effect of chronic total coronary occlusion on treatment strategy. Am J Cardiol. 2005; 95(9):1088-91. [PubMed: 15842978] 
4. Werner GS, Gitt AK, Zeymer U, Juenger C, Towae F, Wienbergen H, Senges J. Chronic total coronary occlusions in patients with stable angina pectoris: impact on therapy and outcome in present day clinical practice. Clin Res Cardiol. 2009; 98(7):435-41. [PubMed: 19294443]

5. Grantham JA, Marso SP, Spertus J, House J, Holmes DR Jr, Rutherford BD. Chronic total occlusion angioplasty in the United States. JACC Cardiovasc Interv. 2009; 2(6):479-86. [PubMed: 19539249]

6. Abbott JD, Kip KE, Vlachos HA, Sawhney N, Srinivas VS, Jacobs AK, Holmes DR, Williams DO. Recent trends in the percutaneous treatment of chronic total coronary occlusions. Am J Cardiol. 2006; 97(12):1691-6. [PubMed: 16765115]

7. Patel VG, Brayton KM, Tamayo A, Mogabgab O, Michael TT, Lo N, Alomar M, Shorrock D, Cipher D, Abdullah S, Banerjee S, Brilakis E. Incidence of Angiographic Success and Procedural Complications in Patients Undergoing Percutaneous Coronary Chronic Total Occlusion Interventions: A Weighted Meta-Analysis of 18,061 Patients from 65 Studies. JACC Cardiovasc Interv. 2013 in press.

8. Thompson CA, Jayne JE, Robb JF, Friedman BJ, Kaplan AV, Hettleman BD, Niles NW, Lombardi WL. Retrograde techniques and the impact of operator volume on percutaneous intervention for coronary chronic total occlusions an early U.S. experience. JACC Cardiovasc Interv. 2009; 2(9): 834-42. [PubMed: 19778771]

9. Morino Y, Kimura T, Hayashi Y, Muramatsu T, Ochiai M, Noguchi Y, Kato K, Shibata Y, Hiasa Y, Doi O, Yamashita T, Morimoto T, Abe M, Hinohara T, Mitsudo K. In-hospital outcomes of contemporary percutaneous coronary intervention in patients with chronic total occlusion insights from the J-CTO Registry (Multicenter CTO Registry in Japan). JACC Cardiovasc Interv. 2010; 3(2):143-51. [PubMed: 20170870]

10. Michael TT, Karmpaliotis D, Brilakis ES, Fuh E, Patel VG, Mogabgab O, Kirkland BL, Lembo N, Kalynych A, Carlson H, Banerjee S, Lombardi W, Kandzari DE. Procedural Outcomes of Revascularization of Chronic Total Occlusion of Native Coronary Arteries (From a Multicenter United States Registry). Am J Cardiol. 2013 in press.

11. Galassi AR, Tomasello SD, Reifart N, Werner GS, Sianos G, Bonnier H, Sievert H, Ehladad S, Bufe A, Shofer J, Gershlick A, Hildick-Smith D, Escaned J, Erglis A, Sheiban I, Thuesen L, Serra A, Christiansen E, Buettner A, Costanzo L, Barrano G, Di Mario C. In-hospital outcomes of percutaneous coronary intervention in patients with chronic total occlusion: insights from the ERCTO (European Registry of Chronic Total Occlusion) registry. EuroIntervention. 2011; 7(4): 472-9. [PubMed: 21764666]

12. Boatman DM, Saeed B, Varghese I, Peters CT, Daye J, Haider A, Roesle M, Banerjee S, Brilakis ES. Prior coronary artery bypass graft surgery patients undergoing diagnostic coronary angiography have multiple uncontrolled coronary artery disease risk factors and high risk for cardiovascular events. Heart Vessels. 2009; 24(4):241-6. [PubMed: 19626394]

13. Hwang MH, Meadows WR, Palac RT, Piao ZE, Pifarre R, Loeb HS, Gunnar RM. Progression of native coronary artery disease at 10 years: insights from a randomized study of medical versus surgical therapy for angina. J Am Coll Cardiol. 1990; 16(5):1066-70. [PubMed: 2229749]

14. Rupprecht HJ, Hamm C, Ischinger T, Dietz U, Reimers J, Meyer J. Angiographic follow-up results of a randomized study on angioplasty versus bypass surgery (GABI trial). GABI Study Group. Eur Heart J. 1996; 17(8):1192-8. [PubMed: 8869860]

15. Aziz S, Stables RH, Grayson AD, Perry RA, Ramsdale DR. Percutaneous coronary intervention for chronic total occlusions: improved survival for patients with successful revascularization compared to a failed procedure. Catheter Cardiovasc Interv. 2007; 70(1):15-20. [PubMed: 17580364]

16. Mohr FW, Morice MC, Kappetein AP, Feldman TE, Stahle E, Colombo A, Mack MJ, Holmes DR Jr, Morel MA, Van Dyck N, Houle VM, Dawkins KD, Serruys PW. Coronary artery bypass graft surgery versus percutaneous coronary intervention in patients with three-vessel disease and left main coronary disease: 5-year follow-up of the randomised, clinical SYNTAX trial. Lancet. 2013; 381(9867):629-38. [PubMed: 23439102]

17. Joyal D, Afilalo J, Rinfret S. Effectiveness of recanalization of chronic total occlusions: a systematic review and meta-analysis. Am Heart J. 2010; 160(1):179-87. [PubMed: 20598990]

18. Borgia F, Viceconte N, Ali O, Stuart-Buttle C, Saraswathyamma A, Parisi R, Mirabella F, Dimopoulos K, Di Mario C. Improved cardiac survival, freedom from mace and angina-related 
quality of life after successful percutaneous recanalization of coronary artery chronic total occlusions. Int J Cardiol. 2012; 161(1):31-8. [PubMed: 21722979]

19. Michael TT, Karmpaliotis D, Brilakis ES, Abdullah SM, Kirkland BL, Mishoe KL, Lembo N, Kalynych A, Carlson H, Banerjee S, Lombardi W, Kandzari DE. Impact of prior coronary artery bypass graft surgery on chronic total occlusion revascularisation: insights from a multicentre US registry. Heart. 2013 published online before print. 


\section{Patients Presenting for Diagnostic Angiography}

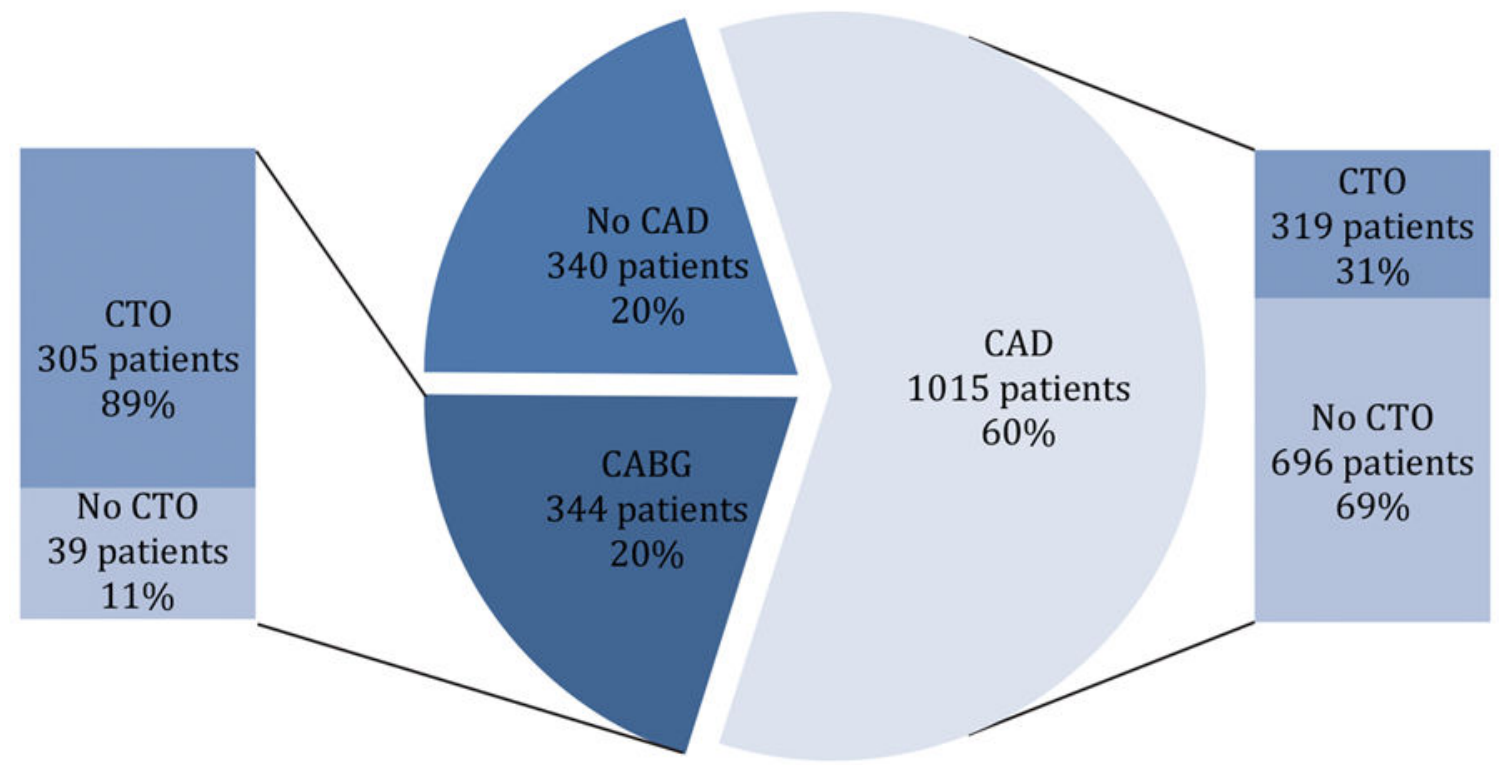

Figure 1.

Patients Presenting for Diagnostic Angiography

Prevalence of coronary artery disease and coronary chronic total occlusions in the study population.

$\mathrm{CABG}=$ coronary artery bypass graft; $\mathrm{CAD}=$ coronary artery disease; $\mathrm{CTO}=$ chronic total occlusion 


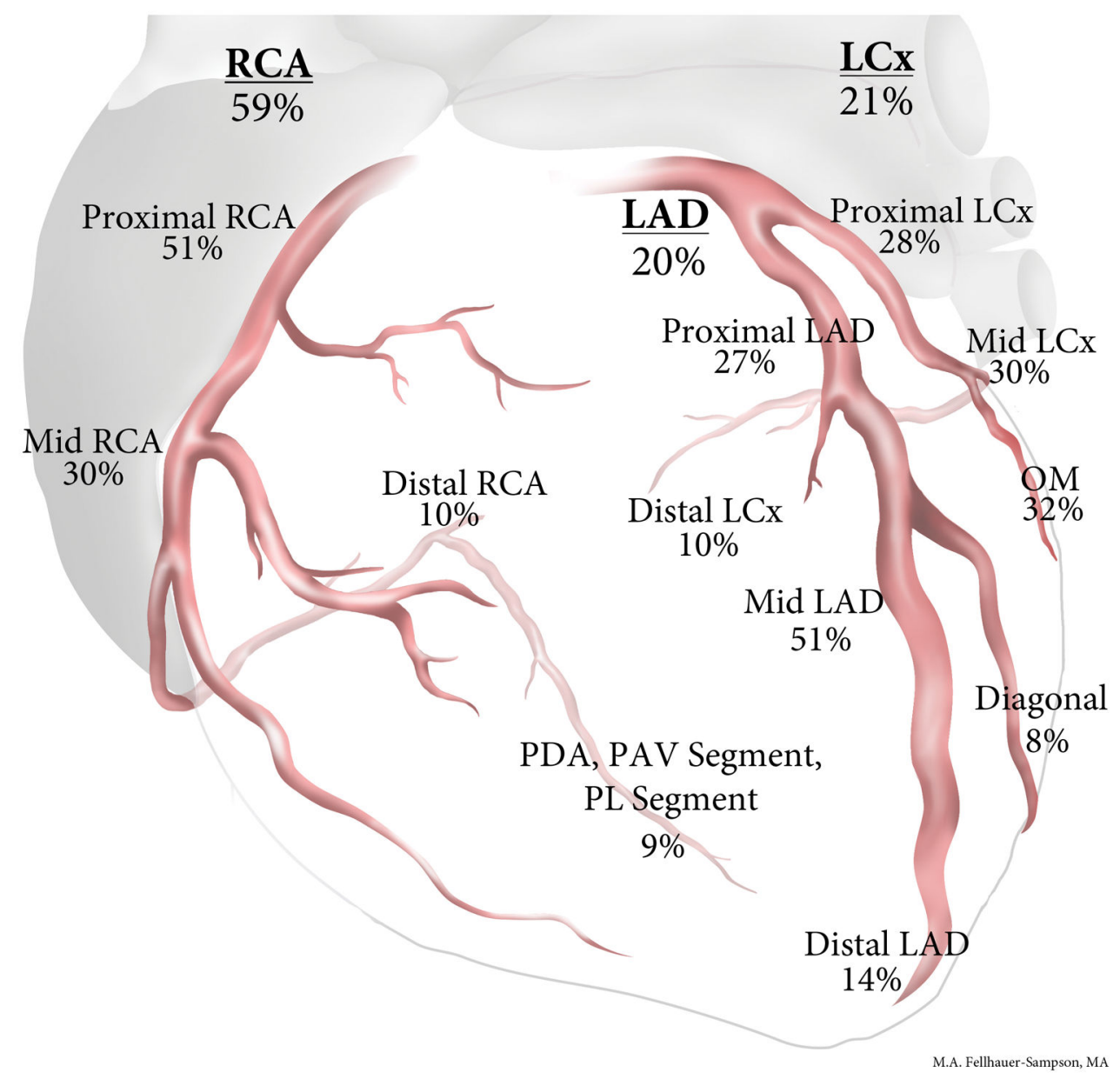

Figure 2.

Distribution of CTOs in patients with one CTO

Distribution of coronary chronic total occlusions among the study patients.

$\mathrm{CTO}=$ chronic total occlusion; $\mathrm{LAD}=$ left anterior descending artery; $\mathrm{LCx}=$ left circumflex artery; $\mathrm{OM}=$ obtuse marginal artery; $\mathrm{PAV}=$ posterior atrio-ventricular vessel; $\mathrm{PDA}=$ posterior descending artery; $\mathrm{PL}=$ posterolateral; $\mathrm{RCA}=$ right coronary artery 


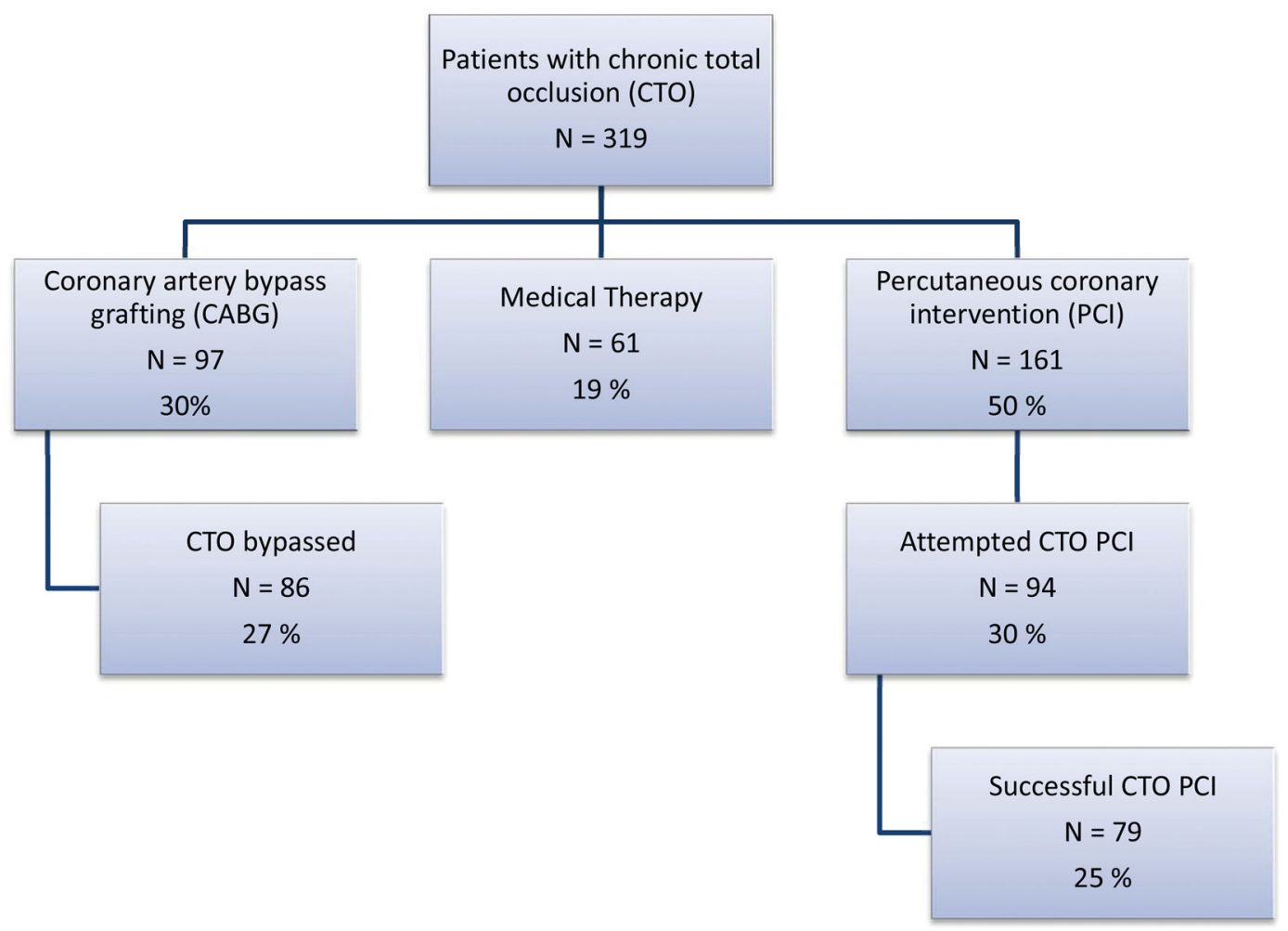

Figure 3.

Revascularization Strategy in non-CABG patients

Flow chart depicting coronary revascularization strategies for patients with coronary chronic total occlusion(s) who did not have prior coronary artery bypass graft surgery.

$\mathrm{CABG}=$ coronary artery bypass graft; $\mathrm{CTO}=$ chronic total occlusion; $\mathrm{PCI}=$ percutaneous coronary intervention 


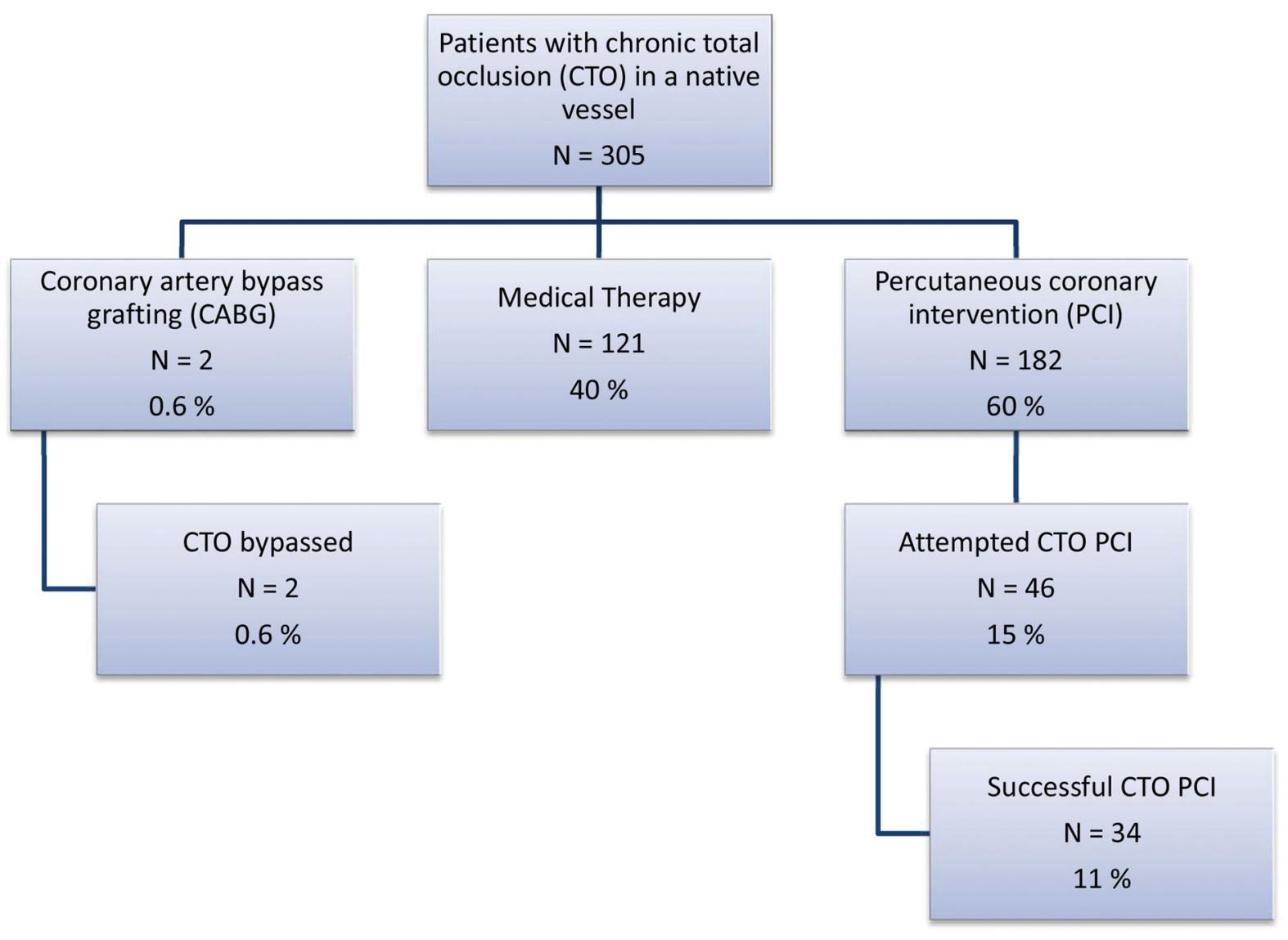

Figure 4.

Revascularization Strategy in prior CABG patients

Flow chart depicting coronary revascularization strategies for patients with coronary chronic total occlusion(s) who had prior coronary artery bypass graft surgery.

$\mathrm{CABG}=$ coronary artery bypass graft; $\mathrm{CTO}=$ chronic total occlusion; $\mathrm{PCI}=$ percutaneous coronary intervention 


\section{Table I}

Baseline characteristics of non-CABG patients with coronary artery disease in the study population, classified according to the presence of a coronary chronic total occlusion.

\begin{tabular}{|c|c|c|c|}
\hline Variable & Non-CTO Group ( $\mathrm{n}=696$ patients) & CTO Group ( $n=319$ patients) & $P$ \\
\hline Age (years) & $64 \pm 9$ & $65 \pm 8$ & 0.07 \\
\hline Male & $687(99 \%)$ & $318(100 \%)$ & 0.14 \\
\hline Ethnicity & & & 0.92 \\
\hline Caucasian & $504(72 \%)$ & $234(73 \%)$ & \\
\hline Black & $152(22 \%)$ & $67(21 \%)$ & \\
\hline Hispanic & $28(4 \%)$ & $14(4 \%)$ & \\
\hline Other & $12(2 \%)$ & $4(1 \%)$ & \\
\hline BMI $\left(\mathrm{kg} / \mathrm{m}^{2}\right)$ & $30 \pm 6$ & $30 \pm 6$ & 0.79 \\
\hline Hypertension & $623(90 \%)$ & $281(88 \%)$ & 0.50 \\
\hline Dyslipidemia & $596(86 \%)$ & $280(88 \%)$ & 0.36 \\
\hline Diabetes mellitus & $317(46 \%)$ & $167(52 \%)$ & 0.04 \\
\hline Prior CVA & $78(11 \%)$ & $55(17 \%)$ & 0.008 \\
\hline Prior CHF & $167(24 \%)$ & $106(33 \%)$ & 0.002 \\
\hline Prior MI & $181(26 \%)$ & $125(39 \%)$ & $<0.001$ \\
\hline Prior PCI & $232(33 \%)$ & $111(35 \%)$ & 0.65 \\
\hline \multicolumn{4}{|l|}{ Tobacco Use } \\
\hline Past & $552(79 \%)$ & $275(86 \%)$ & 0.009 \\
\hline Current & $264(38 \%)$ & $138(43 \%)$ & 0.11 \\
\hline Peripheral arterial disease & $98(14 \%)$ & $77(24 \%)$ & $<0.001$ \\
\hline Family history of early CAD & $176(25 \%)$ & $64(20 \%)$ & 0.07 \\
\hline CKD & $105(15 \%)$ & $55(17 \%)$ & 0.38 \\
\hline Clinical presentation & & & 0.03 \\
\hline Stable angina & $212(30 \%)$ & $118(37 \%)$ & \\
\hline Acute coronary syndrome & $259(37 \%)$ & $102(32 \%)$ & \\
\hline Other & $225(32 \%)$ & $99(31 \%)$ & \\
\hline Ejection fraction (\%) & & & $<0.001$ \\
\hline LVEF $\geq 40 \%$ & $551(82 \%)$ & $211(66 \%)$ & \\
\hline LVEF $<40 \%$ & $123(18 \%)$ & $107(34 \%)$ & \\
\hline 3-vessel disease & $140(20 \%)$ & $177(55 \%)$ & $<0.001$ \\
\hline Left Main disease & $73(10 \%)$ & $59(19 \%)$ & $<0.001$ \\
\hline Treatment chosen & & & $<0.001$ \\
\hline Medical/No Intervention & $216(31 \%)$ & $61(19 \%)$ & \\
\hline PCI to any vessel & $368(53 \%)$ & $161(50 \%)$ & \\
\hline CABG & $112(16 \%)$ & $97(30 \%)$ & \\
\hline \multicolumn{4}{|l|}{ Medications } \\
\hline Aspirin & $660(95 \%)$ & $316(99 \%)$ & 0.001 \\
\hline Beta-blocker & $635(91 \%)$ & $305(96 \%)$ & 0.01 \\
\hline ACEI/ARB & $506(73 \%)$ & $227(71 \%)$ & 0.61 \\
\hline
\end{tabular}




\begin{tabular}{lccc}
\hline Variable & Non-CTO Group $(\mathbf{n}=\mathbf{6 9 6}$ patients) & CTO Group (n= 319 patients) & $\boldsymbol{P}$ \\
\hline Statin & $652(94 \%)$ & $307(96 \%)$ & 0.15 \\
Long-acting nitrate & $152(22 \%)$ & $76(24 \%)$ & 0.48 \\
Insulin & $147(21 \%)$ & $78(24 \%)$ & 0.24
\end{tabular}

Data is presented as mean \pm standard deviation or number (percent).

$\mathrm{ACEI}=$ angiotensin-converting enzyme inhibitor; $\mathrm{ARB}=$ angiotensin-receptor blocker; $\mathrm{BMI}=$ body mass index; $\mathrm{CABG=coronary}$ artery bypass graft; $\mathrm{CAD}=$ coronary artery disease; $\mathrm{CHF}=$ congestive heart failure; $\mathrm{CKD}=$ chronic kidney disease; $\mathrm{CTO}=$ chronic total occlusion; $\mathrm{CVA}=$ cerebrovascular accident; $\mathrm{LVEF}=$ left ventricular ejection fraction; $\mathrm{MI}=$ myocardial infarction; $\mathrm{PCI}=$ percutaneous coronary intervention 


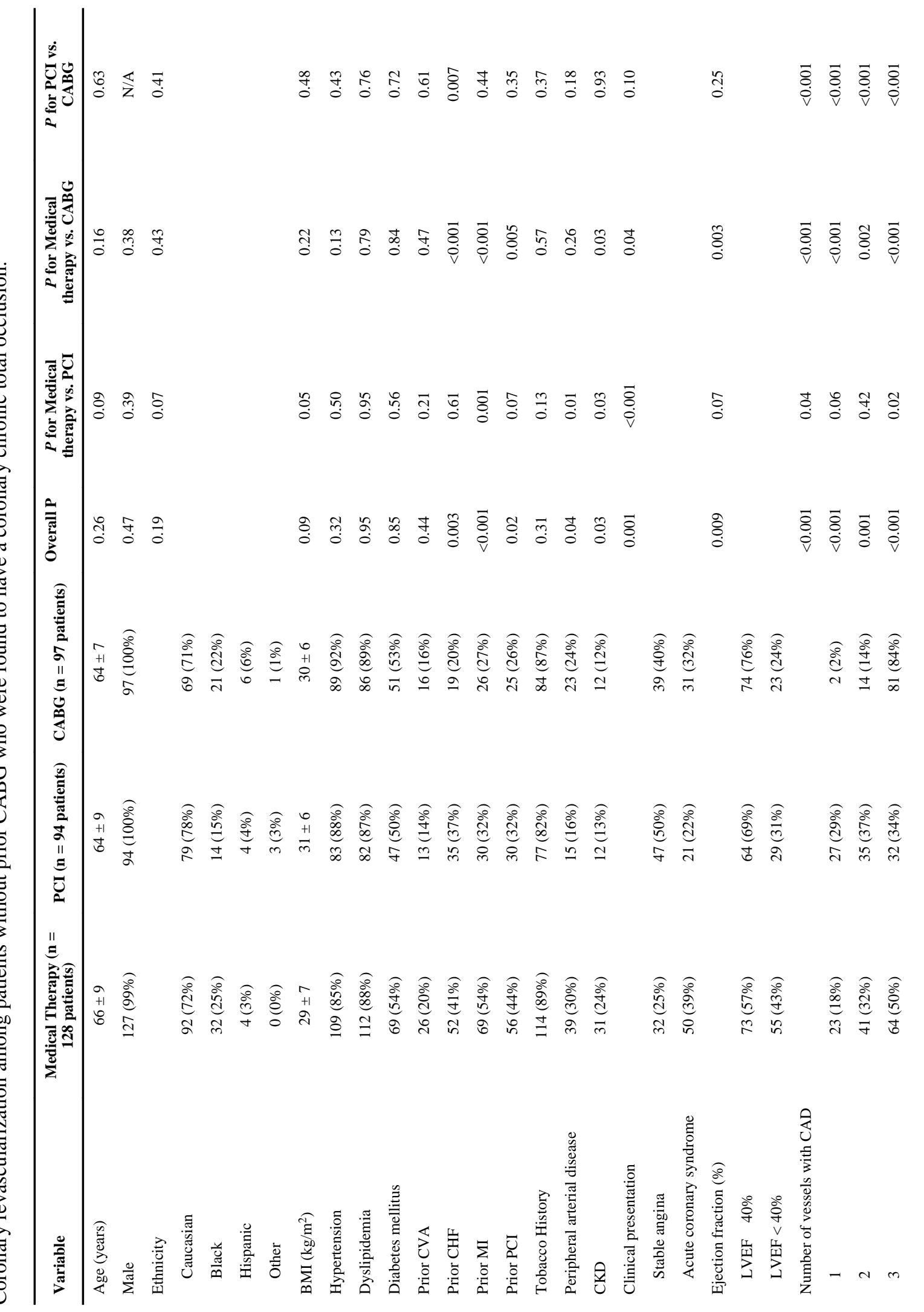


Jeroudi et al.

Page 16

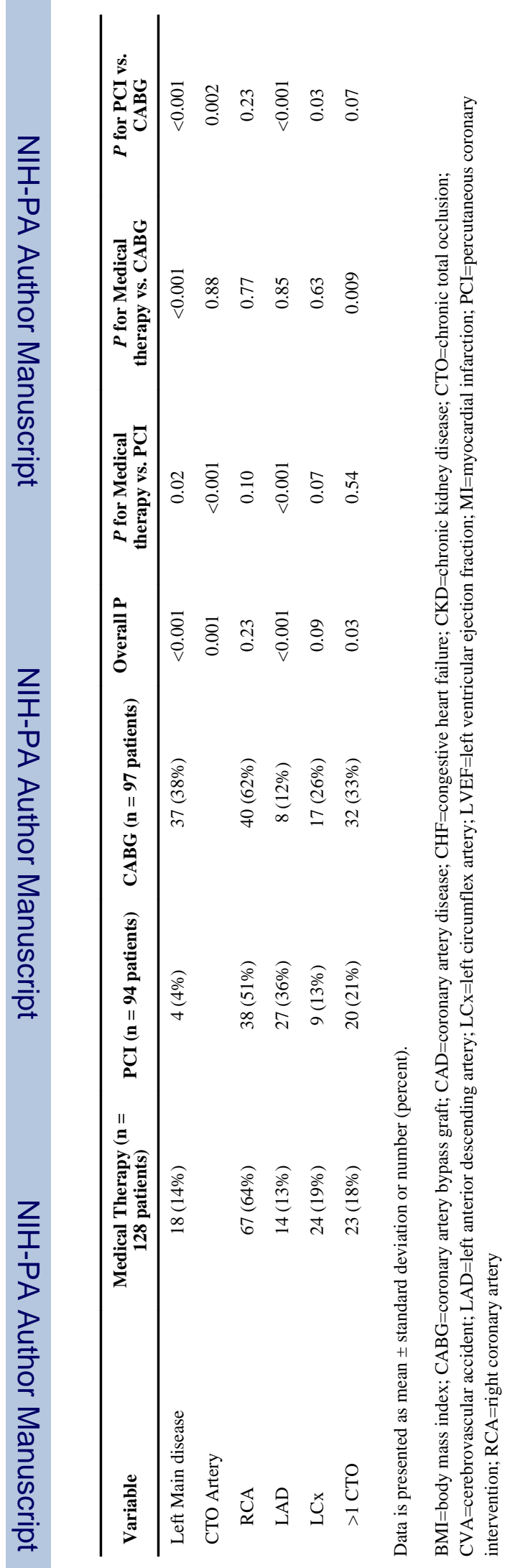

Catheter Cardiovasc Interv. Author manuscript; available in PMC 2015 October 01. 


\section{Table III}

Published studies reporting the prevalence of coronary chronic total occlusions.

\begin{tabular}{|c|c|c|c|}
\hline & Country & $\begin{array}{c}\text { CTO prevalence among CAD patients without } \\
\text { prior CABG }\end{array}$ & $\begin{array}{c}\text { CTO prevalence among prior CABG } \\
\text { patients }\end{array}$ \\
\hline Fefer et al.(1) & Canada & $18.4 \%$ & $54 \%$ \\
\hline Kahn et al.(2) & USA & $35 \%$ & NR \\
\hline Werner et al.(4)* & Germany & $33 \%$ & NR \\
\hline Christofferson et al.(3) ${ }^{\dagger}$ & USA & $52 \%$ & NR \\
\hline Present study & USA & $31 \%$ & $89 \%$ \\
\hline
\end{tabular}

